Estes, D., and Larson, D. L. (1965). Systemic lupus erythematosus and pregnancy. Clinical Obstetrics and Gynceology, $8,307-321$.

Hughes, G. R. V. (1974). Systemic lupus erythematosus. British Journal of Hospital Medicine, 12, 309-319.

Jackson, R. (1964). Discoid lupus in a newborn infant of a mother with lupus erythematosus. Pediatrics, 33, 425-430.

Jokinen, E. J., and Jankala, E. O. (1970). Antitissue antibodies in monozygotic twins with systematic lupus erythematosus. Annals of Rheumatic Diseases 29, 677-680.

McGee, C. D., and Makowski, E. L. (1970). Systemic lupus erythematosus in pregnancy. American Journal of Obstetrics and Gynecology, 107, 1008-1012.

Reed, W. B., May, S. B., and Tuffanelli, D. L. (1967). Discoid lupus erythematosus in a newborn. Archives of Dermato$\log y, 96,64-66$.

Scott, J. S. (1976). Transient manifestations of immunological diseases in the child. Lancet, 1, 78-80.

Siegal, M., and Lee, S. L. (1973). The epidemiology of systemic lupus erythematosus. Seminars in Arthritis and Rheumatism, 3, 1.

Requests for reprints to $\mathrm{Dr}$ J. S. Fitzsimmons, Genetic Counselling Clinic, City Hospital, Hucknall Road, Nottingham NG5 1PB.

\section{Regular G21-trisomy in 3 sibs from mother with trisomy 21 mosaicism $^{1}$}

SUMMARY This paper describes a family with 3 affected sibs with regular trisomy 21 Down syndrome. The condition seems to be transmitted from a phenotypically normal mother in whom G-trisomy mosaicism was identified. Giemsa banding depicted trisomy 21 mosaicism in cells from the mother. Chromosomes from the children showed a trisomy 21 in all the cells analysed.

In 1962, Smith et al. first described trisomy 21 Down syndrome associated with maternal mosaicism. Subsequently trisomy Down syndrome associated with maternal G-trisomy mosaicism has been reported in at least 12 instances. Aarskog in 1969 described a family with 2 affected sibs and made a review of cases published so far. In 1 of the families of this series the mother gave birth to 3 consecutive children with Down syndrome. Recently Kaffe et al. (1974) reported a case of trisomy 21 mosaicism in a

${ }^{1}$ This work was supported by grants M-43-76 and M-55-76 from the Consejo de Desarrollo Científico y Humanístico. Universidad de los Andes, Mérida, Venezuela.

Received for publication 2 June 1976 a woman with 2 children with trisomy 21 Dow syndrome.

We would like to present a family in which 3 sis show trisomy 21 Down syndrome. Chromosomes from the mother showed trisomy 21 mosaicisio. Giemsa banding performed by the method $\overline{\mathcal{H}_{f}}$ Seabright (1971), confirmed the presence of an extra $\mathrm{G}$ chromosome in the trisomic cells.

\section{Case reports}

The probands, 1 boy and 2 girls, were first seen $\overrightarrow{\text { af }}$ the genetics clinic at the ages of 13,10 , and 8 . because of findings suggesting Down syndrome. They we the second, third, and fourth of 4 children (Fig. L) The first one appeared as a normal 18-year-of youngster. Each affected child showed clinical featuriss of Down syndrome such as brachycephaly, epicanthas folds, mongoloid slant of palpebral fissures, lowplaced dysplastic ears, hypotonia, and typical dermatoglyphs.

The mother was 39 years old when she was seen for the first time in 1975. She was the eldest of ca sibship of 6 . Her mother was 26 years old and her father 23 years old when she was born. A paterna aunt gave birth to a child with clinical features of Down syndrome at the age of 41 . She had 4 up eventful pregnancies, the first one at the age of 19 an the last one when she was 29 years old, and no abot:tions. Her first pregnancy ended with the birth of normal boy. Five years later, at the age of 24 years, sle gave birth to a boy with typical features of Dow syndrome. She became pregnant again at the ages of 7 and 29 years and gave birth to 2 more children, both of them with clinical stigmata of Down syndromer. There was no history of drug ingestion, radiation exposure, or viral infection. Each child belongs to different father. At the time of the interview in 197\%, she was 39 years old. She displayed no stigmata of Down syndrome, and her intelligence was considere normal.

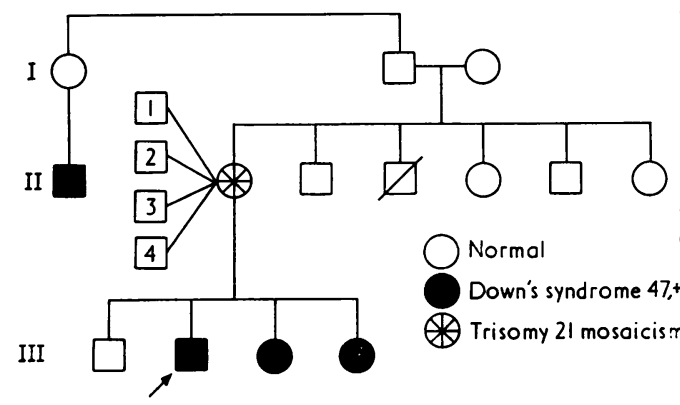

Fig. 1 Pedigree of the family. 


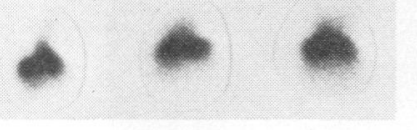

21

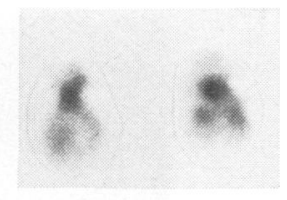

22
Fig. 2 Partial karyotype of $G$ group chromosomes from the mother with Giemsa banding.

\section{CYTOGENETICS}

Chromosome analysis was carried out on 2 different occasions from peripheral leucocyte cultures of the mother. Giemsa banding was performed by the method of Seabright (1971). Mosaicism 46,XX/47, $\mathrm{XX}+\mathrm{G}$ was found, there being 12 cells with a 47 , $\mathrm{XX}+\mathrm{G}$ karyotype out of 200 cells examined. The 3 affected children showed regular G-21 trisomy in all the cells examined. The oldest child who appeared to be a normal boy was found to have a 46,XY karyotype. The fathers were not available for examination. The extra $G$ chromosome in the trisomic cells was identified by Giemsa banding (Fig. 2).

\section{Discussion}

In addition to these 3 members of the present family, there have been, to our knowledge, 12 more reported cases of trisomy Down syndrome in which maternal trisomy 21 mosaicism has been identified. Of these, 9 cases were isolated; we were only able to find 3 reports of trisomy 21 Down syndrome in sibs from phenotypically normal mothers with trisomy 21 mosaicism (Smith et al., 1962; Aarskog, 1969; Kaffe et al., 1974). In all the cases, the phenotypically normal women have given birth to children with trisomy 21 Down syndrome between the ages of 19 and 32 . The proportion of trisomic cells has varied from 5 to $29 \%$, and in the cases reviewed by Aarskog (1969), there were only 2 mothers with stigmata of Down syndrome.

Cytogenetic analysis of 14 young mothers, with ages between 17 and 29 , from 43 families with children with trisomy 21 Down syndrome has failed to show any abnormal karyotype, with the exception of the present family (personal observation).

Two different mechanisms have been suggested to explain the origin of mosaic trisomy, from a normal zygote containing 46 chromosomes or from an abnormal zygote containing 47 chromosomes. In the first case, mitotic nondisjunction takes place after the first cleavage division of a normal zygote containing 46 chromosomes. Thus, 3 types of cells each with a different chromosome constitution are formed: $45,-21$, which is not viable; 46 (normal) and $47,+21$. The second mechanism is meiotic non-disjunction during parental gametogenesis, by which an abnormal zygote containing 47 chromosomes, with a G 21 trisomy, is formed. After the first mitotic division one of the extra chromosomes would then be lost, giving rise to two different cells lines in the new individual. This last theory seems to be more admissible, since it has been observed that the birth of children with trisomy 21 mosaicism is commonly associated with advanced maternal age (Penrose and Smith, 1966). Therefore, an age-dependent factor may be involved in the formation, by primary non-disjunction, of a zygote with an extra chromosome.

According to Penrose (1963), Down syndrome may be classified in two groups, the maternal age-dependent group and the age-independent group. Most of the familial cases will be found in the age-independent group. Trisomy 21 Down syndrome associated with maternal trisomy mosaicism would be placed in the latter group. Thus, trisomy 21 mosaic mothers carry a considerably higher risk of having children with trisomy 21 Down syndrome. In addition to that, their risk of recurrence is greater than would be expected in non-mosaic women, as is suggested from the findings in the present family and those previously reported by Smith et al. (1962), Aarskog (1969), and by Kaffe et al. (1974).

It must be stressed that after the birth of a mongol child to a young couple, chromosome analysis should be carried out in both parents in order to rule out parental mosaicism.

\section{A. Osuna ANd A. Moreno Departamento de Medicina, Unidades de Endo- crinología y Genética, Facultad de Medicina, Universidad de los Andes, Mérida, Venezuela.}

\section{References}

Aarskog, D. (1969) Down's syndrome transmitted through maternal mosaicism. Acta Paediatrica Scandinavica, 58, 609-614.

Kaffe, S., Hsu, L. Y. F., and Hirschhorn, K. (1974). Trisomy 21 mosaicism in a woman with two children with trisomy 21 Down's syndrome. Journal of Medical Genetics, 11, 378-379.

Penrose, L. S. (1963). The Biology of Mental Defect. Sidgwick and Jackson London.

Penrose, L. S., and Smith, G. F. (1966) Down's Anomaly. Churchill, London.

Seabright, M. (1971). A rapid banding technique for human chromosomes. Lancet, 2, 971-972.

Smith, D. W., Thermon, E. M., Patau, K. A., and Inhorer, S. L. (1962). Mosaicism in mother of two mongoloids. American Journal of Diseases of Chidren, 104, 534.

Requests for reprints to Dr Alfonso Osuna, Facultad de Medicina, Universided de los Andes, Apartado No. 156, Mérida, Venezuela. 